\title{
Microstructure and properties of Ti-Nb-V-Mo-alloyed high chromium cast iron
}

\author{
YOUPING MA, XIULAN LI*, YUGAO LIU ${ }^{\dagger}$, SHUYI ZHOU and XIAOMING DANG \\ School of Metallurgical Engineering, Xi' an University of Architecture and Technology, Xi'an 710055, China \\ ${ }^{\dagger}$ School of Mechanical and Electrical Engineering, Qingdao Agricultural University, Qingdao 266109, China
}

MS received 28 March 2012; revised 20 June 2012

\begin{abstract}
The correlations of microstructure, hardness and fracture toughness of high chromium cast iron with the addition of alloys (titanium, vanadium, niobium and molybdenum) were investigated. The results indicated that the as-cast microstructure changed from hypereutectic, eutectic to hypoeutectic with the increase of alloy contents. Mo dissolved in austenite and increased the hardness by solid solution strengthening. TiC and NbC mainly existed in austenite and impeded the austenite dendrite development. $\mathrm{V}$ existed in multicomponent systems in forms of $\mathrm{V}$ alloy compounds $\left(\mathrm{VCrFe}_{8}\right.$ and $\left.\mathrm{VCr}_{2} \mathrm{C}_{2}\right)$. With the increase of alloy additions, carbides size changed gradually from refinement to coarseness, hardness and impact toughness were increased and then decreased. Compared with the fracture toughness $\left(6 \mathrm{~J} / \mathrm{cm}^{2}\right)$ and hardness $(50 \cdot 8 \mathrm{HRC})$ without any alloy addition, the toughness and hardness at $0.60 \mathrm{~V}-0.60 \mathrm{Ti}-0.60 \mathrm{Nb}-0.35 \mathrm{Mo}(\mathrm{wt} \%)$ additions were improved and achieved to $11 \mathrm{~J} / \mathrm{cm}^{2}$ and $58.9 \mathrm{HRC}$, respectively. The synergistic roles of $\mathrm{Ti}, \mathrm{Nb}, \mathrm{V}$ and Mo influenced the solidification behaviour of alloy. The refinement of microstructure and improvement of carbides morphologies, size and distribution improved the impact toughness.
\end{abstract}

Keywords. High chromium cast iron; fracture toughness; microstructure refinement.

\section{Introduction}

High chromium cast irons (HCCI) are known as excellent wear-resistant materials, which have been widely applied in mineral processing, metallurgical, cement and electric power industries (Labrecque and Gagne 1998; Izciler and Celik 2000; Xie et al 2010). The exceptional wear resistance of HCCI is attributed to hard chromium carbides embedded in relatively soft austenitic/martensitic matrix. When chromium contents exceeded $12 \mathrm{wt} \%$, interconnected $\mathrm{MC}_{3}$ type carbides of conventional cast irons are replaced by rodshaped and isolated $\mathrm{M}_{7} \mathrm{C}_{3}$ carbides (Powell 1980), leading to improvement of impact toughness, ductility and fatigue resistance. The matrix provides sufficient mechanical support to prevent the carbides from cracking and spalling. Carbides in $\mathrm{HCCI}$ are responsible for good abrasion resistance. However, the main $\mathrm{M}_{7} \mathrm{C}_{3}$ carbides in HCCI are hard and brittle and can provide an easy path for crack propagation. This limits its applications, particularly in considerable impact condition. In order to widen the application of HCCI, extend their service life and minimize the maintenance cost, the current interests in research and development were focused on alloyings (Mousavi Anijdan and Bahrami 2007; Chunga et al 2009), modification treatments (Zhi et al 2008c); different cast techniques (Lu et al 2003; Dai et al 2010), heat treatments (Liu and Wang 2007; Qingyu et al 2009). In all researches, the most significant interest in HCCI pivoted

\footnotetext{
*Author for correspondence (hhqlx1@163.com)
}

around carbides. Although the researches on HCCI have been kept for many years without interruption, there is still no breakthrough in sight.

Effect of only one alloy element on HCCI has been investigated by several authors (Qu et al 2008; Zhi et al 2008a,b). $\mathrm{Nb}$, $\mathrm{Ti}$ and $\mathrm{Ce}$ were reported to refine carbides, morphology of carbides was improved with the addition of suitable amounts. $\mathrm{V}$ existed in $\mathrm{Fe}-\mathrm{Cr}-\mathrm{C}-\mathrm{V}$ system in the form of $\mathrm{M}_{6} \mathrm{C}_{5}$ carbides. $\mathrm{V}$ additions refined the microstructure of $19.0 \mathrm{wt} \% \mathrm{Cr}-2.9 \mathrm{wt} \% \mathrm{C}$ irons by the reduced width of austenite dendrite arms and the reduced size of eutectic $\mathrm{M}_{7} \mathrm{C}_{3}$ carbides (Filipovic et al 2011). Here $25 \mathrm{wt} \% \mathrm{Cr}-3.15 \mathrm{wt} \% \mathrm{C}$ alloy was selected for the present study. The general purpose of this study is to investigate the additions of multi-alloying elements on the microstructure refinement and properties so as to provide experimental data and theoretical foundations for further developing chromium alloys.

\section{Experimental}

In the present investigation, $\mathrm{Fe}-\mathrm{Cr}-\mathrm{C}$ alloys were produced by melting low carbon ferrochrome, steel scrap, low silicon pig iron and graphite. Alloys were melted in $30 \mathrm{~kg}$-capacity high frequency induction furnace. The melting temperature was heated to $1753 \mathrm{~K}$. When all alloys were melted in the furnace, pure aluminum was added to deoxidize. After that, ferro alloys such as $\mathrm{Fe}-52 \% \mathrm{~V}, \mathrm{Fe}-30 \% \mathrm{Ti}, \mathrm{Fe}-67.2 \% \mathrm{Nb}$ and $\mathrm{Fe}-60 \%$ Mo were added. The molten alloy was held at $1373 \mathrm{~K}$ for $30 \mathrm{~min}$ for homogenization of temperature 
and composition. The melting was subsequently raised to $1753 \mathrm{~K}$, after removal of any dross and slag, the melt was poured at $1693 \mathrm{~K}$ into a sand mold with a dimension of $11 \times 11 \times 56 \mathrm{~mm}$. Four specimens with different alloy elements were obtained. For convenience, they were referred to as "A", "B", "C" and "D". Considering that the synthetical effects of alloy elements (Inthidech and Boonmak 2010), the maximum additions of alloy element contents was D alloy. Table 1 shows chemical compositions of the four white irons used for the study.

The specimens for optical microscope examinations were prepared using standard metallographic techniques (etched with aquaregia). The unnotched impact specimens $(10 \times 10 \times 55 \mathrm{~mm})$ for impact test were cut from castings described above. The microstructure observation of

Table 1. Chemical compositions of tested alloys (wt \%).

\begin{tabular}{lllllll}
\hline & \multicolumn{6}{c}{ Chemical composition (mass \%) } \\
\cline { 2 - 7 } Alloy & $\mathrm{C}$ & $\mathrm{Cr}$ & $\mathrm{V}$ & $\mathrm{Ti}$ & $\mathrm{Nb}$ & $\mathrm{Mo}$ \\
\hline $\mathrm{A}$ & $3 \cdot 21$ & 24.87 & 0 & 0 & 0 & 0 \\
$\mathrm{~B}$ & $3 \cdot 18$ & 25.02 & 0.30 & 0.30 & 0.30 & 0.15 \\
$\mathrm{C}$ & $3 \cdot 13$ & 25.06 & 0.60 & 0.60 & 0.60 & 0.35 \\
D & $3 \cdot 10$ & $25 \cdot 10$ & 0.90 & 0.90 & 0.90 & 0.50 \\
\hline
\end{tabular}

specimens was performed utilizing GX-51 OLYMPUS optical microscope. Carbides and impact fracture surfaces were observed by scanning electron microscopy (S-3400N). The composition analysis was carried out by energy dispersive spectrum (EDS) attached to SEM. The phase constituents of the alloy were determined by X-ray diffraction (XRD). The bulk hardness of the specimen was measured with HR150 Rockwell Hardometer. Test results were repeated five times under same conditions to ensure reproducibility. The impact toughness value was determined using 150-J impact testing machine (MK-36).

\section{Results and discussion}

\subsection{Influence of additional alloy elements on solidification microstructure}

Figure 1 shows microstructures of the as-cast HCCI with different alloy elements contents. Figure 1(a) is the initial state of A alloy without alloy elements additions. This was a typical hypereutectic microstructure of HCCI, which consisted of primary $\mathrm{M}_{7} \mathrm{C}_{3}$ carbides, eutectic $\mathrm{M}_{7} \mathrm{C}_{3}$ carbides and eutectic austenite. The addition of small amount of Mo solid solution in austenite was to improve the hardenability. EDS patterns of B alloy (figure 2) showed that Mo elements mainly existed in austenite.
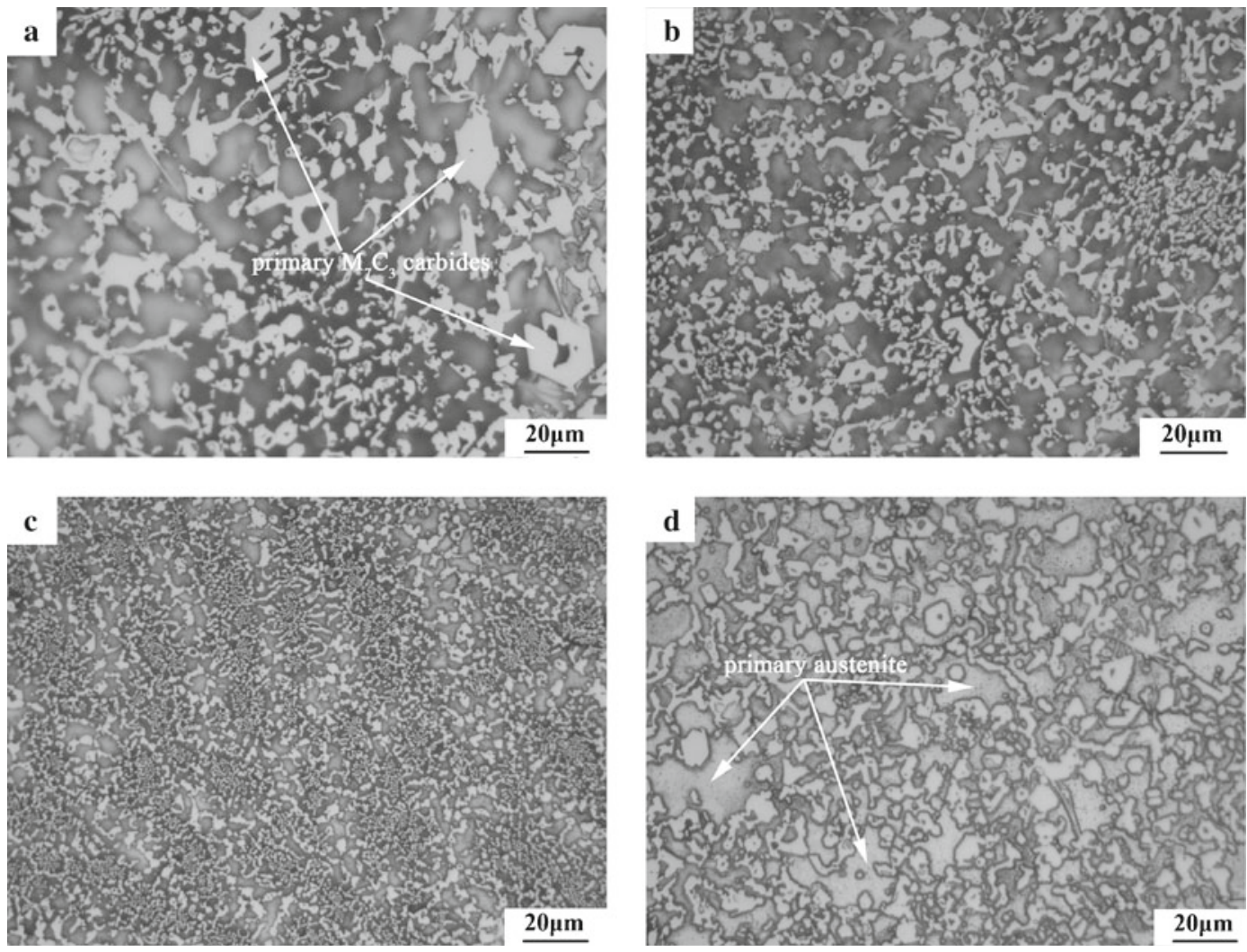

Figure 1. Metallographs of alloys in as-cast condition: (a) A alloy; (b) B alloy; (c) C alloy and (d) D alloy. 

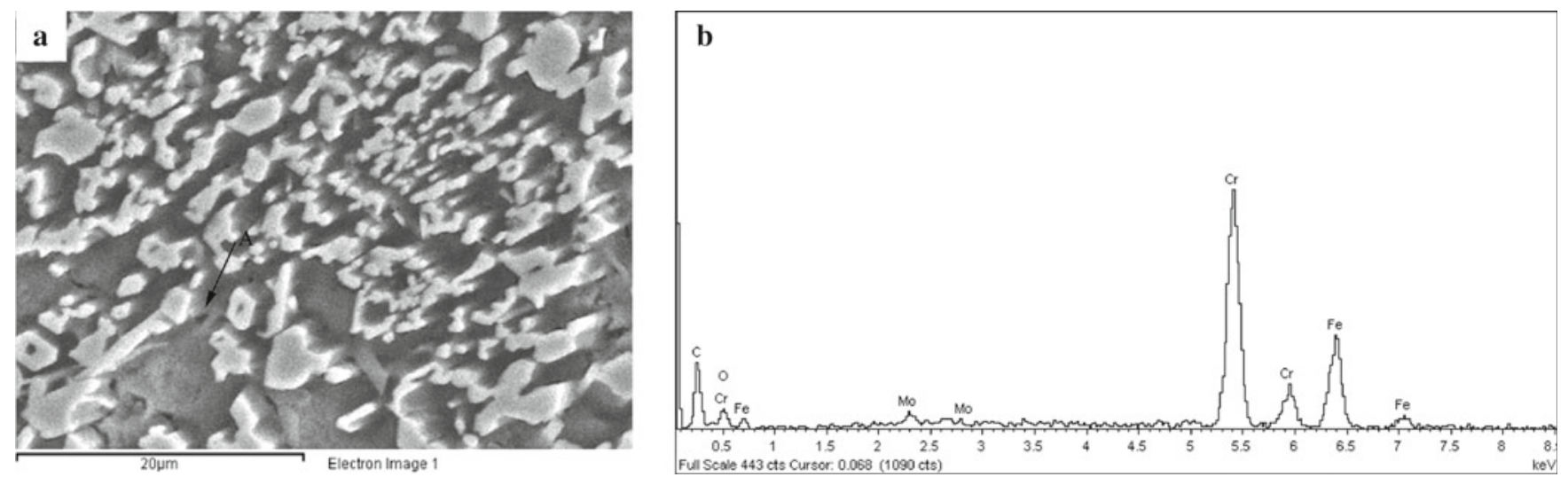

Figure 2. (a) SEM micrograph of B alloy and (b) EDS analysis of point A in figure 2(a) indicating that it was solute molybdenum in austenite.

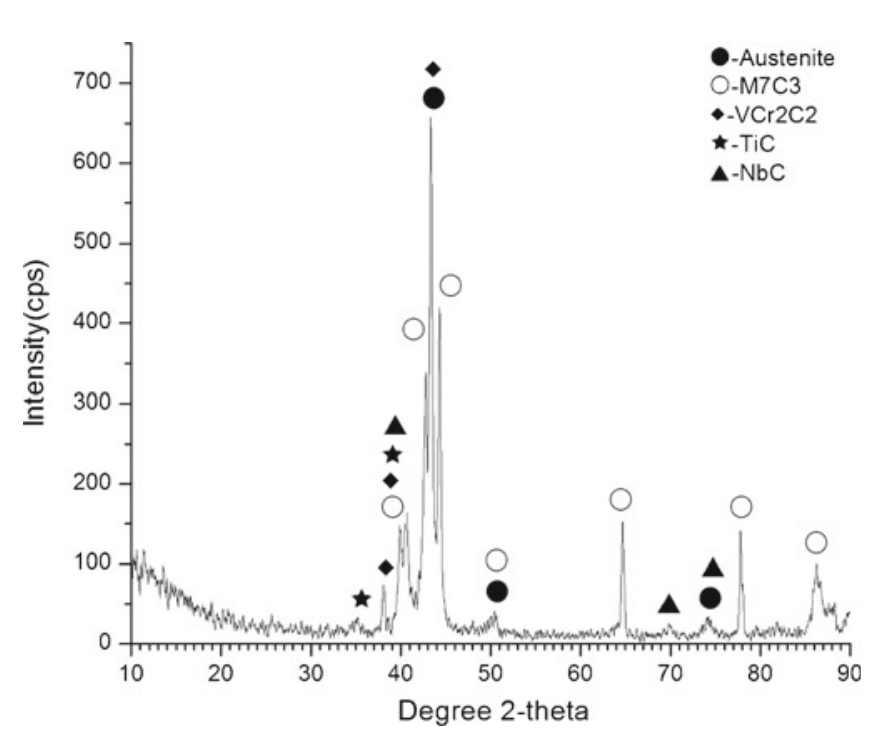

Figure 3. XRD diffraction patterns of $\mathrm{C}$ alloy.
As the amounts of alloy elements increased, microstructure evolved from a hypereutectic structure (figure 1(a)) and eutectic one (figure 1(c)) to hypoeutectic one (figure 1(d)). The carbides were refined gradually and carbides morphology obviously improved. C alloy exhibited the best effect, the equivalent diameter of carbides was the smallest and the distribution of carbides was reasonably uniform. XRD patterns of $\mathrm{C}$ alloy (figure 3) confirmed the presence of $\mathrm{M}_{7} \mathrm{C}_{3}$ carbides, austenite, $\mathrm{VCr}_{2} \mathrm{C}_{2}$ and small amounts of $\mathrm{NbC}$ and TiC. SEM micrographs (figures 4(a) and 5(a)) revealed that $\mathrm{TiC}$ and $\mathrm{NbC}$ were characterized by small and round white particles. $\mathrm{TiC}$ particles were smaller than $\mathrm{NbC}$ particles and located in austenite near $\mathrm{M}_{7} \mathrm{C}_{3}$ carbides, while $\mathrm{NbC}$ mainly existed in the centre of austenite matrix, which was consistent with the reported results (Li et al 1996).

However, when the amounts of alloy elements reached that of the D alloy, the as-cast microstructure was hypoeutectic (figure 1(d)). Figure 6 illustrates XRD patterns of $\mathrm{D}$ alloy, which demonstrates that there are also prominent peaks of $\mathrm{VCrFe}_{8}$ in the alloy besides the phases of $\mathrm{C}$ alloy.
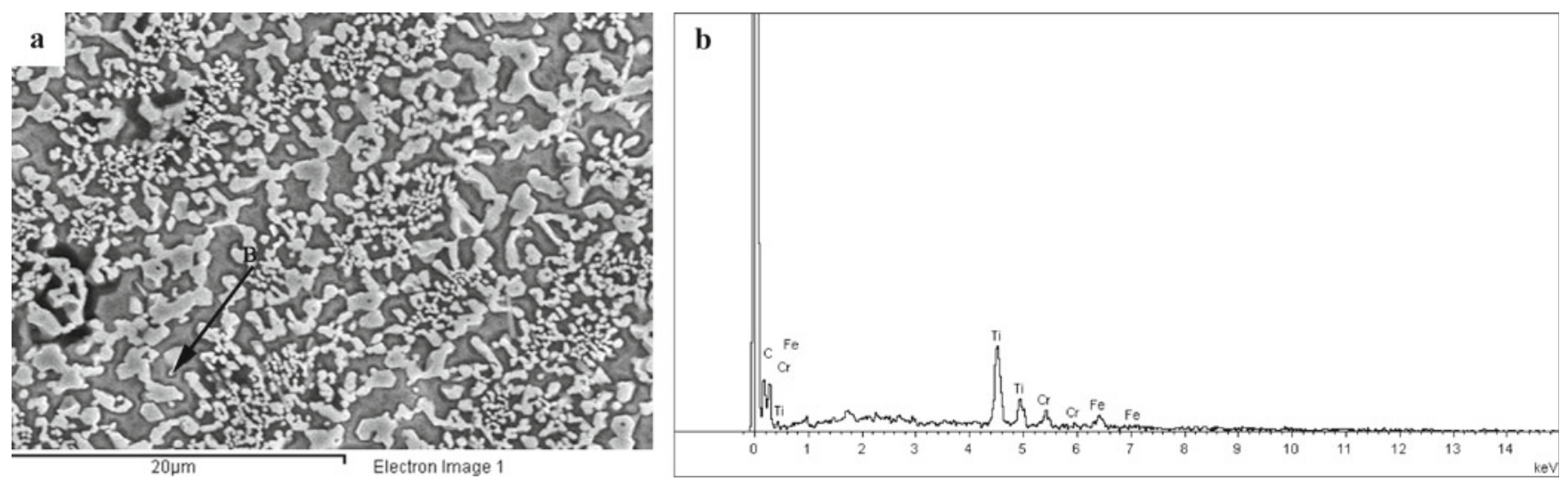

Figure 4. SEM micrograph of $\mathrm{C}$ alloy and EDS analysis of point B. EDS results indicated that point $\mathrm{B}$ was rich in Ti and C, XRD (figure 3) and EDS indicated that white small particles in point B was TiC. 

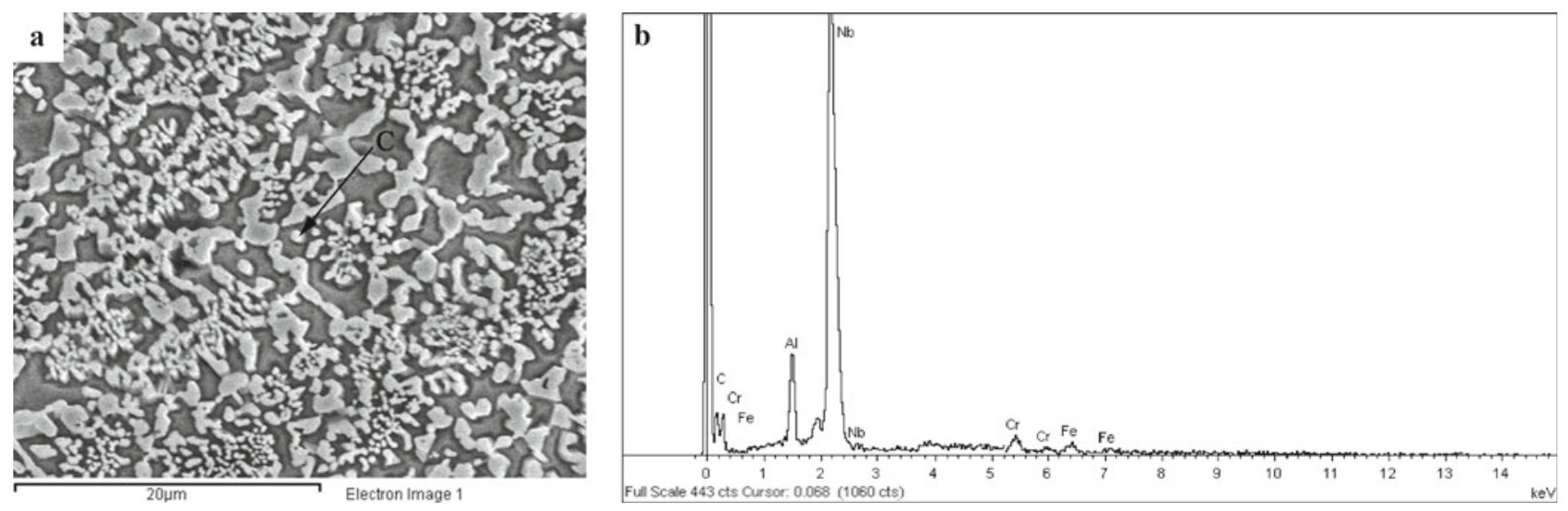

Figure 5. Another SEM micrograph of C alloy and EDS analysis of point C. XRD (figure 3) and EDS results confirmed that particles in point $\mathrm{C}$ was $\mathrm{NbC}$.

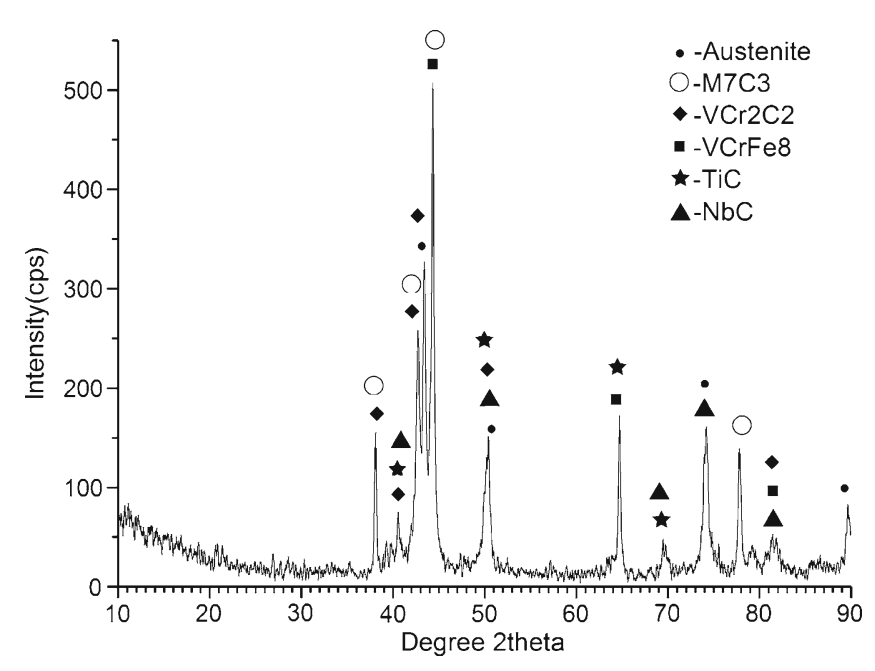

Figure 6. XRD patterns of D alloy.
The dependent VC particle was not observed. EDS spectrum (figure 7(b)) reveals that there are prominent peaks of $\mathrm{V}$ in point D. This is in agreement with the work of Dupin et al (1982). They had previously observed that an addition of $1 \mathrm{wt} \% \mathrm{~V}$ in $20 \% \mathrm{Cr}-2.6 \% \mathrm{C}$ iron did not produce any vanadium carbide precipitation but had a refining effect on the eutectic carbide.

\subsection{Analysis of microstructure refinement}

Previous works (Qu et al 2008; Zhi et al 2008a,b) have shown that the first precipitated particles ( $\mathrm{TiC}, \mathrm{NbC}$ ) acted as the heterogeneous substrates of $\mathrm{M}_{7} \mathrm{C}_{3}$ carbides, resulting in significant refinement of $\mathrm{M}_{7} \mathrm{C}_{3}$ carbides. However, experimental results were not consistent with those reports. The cores of $\mathrm{TiC}, \mathrm{VC}$ and $\mathrm{NbC}$ were not observed in $\mathrm{M}_{7} \mathrm{C}_{3}$ carbides. The addition of $\mathrm{V}$ decreased liquid temperature and increased eutectic temperature, thus eutectic solidification temperature interval decreased (Filipovic et al 2011).
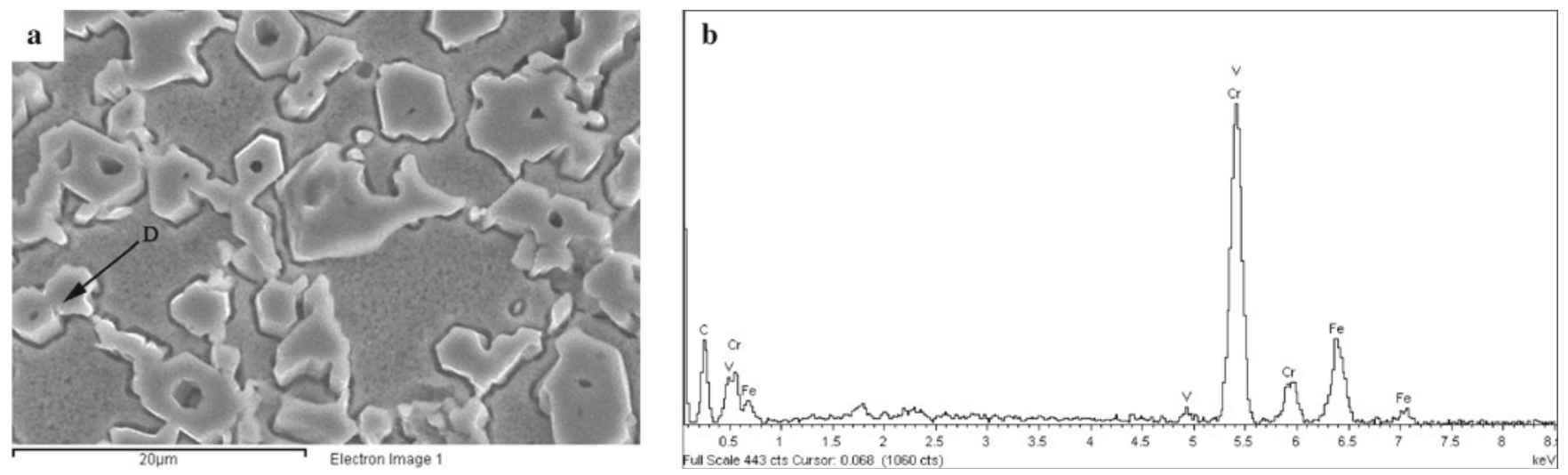

Figure 7. SEM micrograph of D alloy and EDS analysis of point D. 
According to the work of Ogi et al (1982), the carbides spacing increased with the increase of eutectic temperature range, so the decreasing eutectic temperature interval effectively reduced the carbides spacing due to the addition of $\mathrm{V}$.

$\mathrm{Nb}$ existed as a solid solution in austenite and easily aggregated at grain boundary of austenite and caused internal adsorption (Fiset et al 1993), which hindered progress of austenite interface, thus, decreasing the austenite growth rate. When $\mathrm{Nb}$ addition exceeded maximum solid solution in austenite, $\mathrm{NbC}$ was formed, a local area around first precipitated $\mathrm{NbC}$ became impoverished in carbon, leading to high austenite precipitated temperature. Therefore, austenite easily nucleated around $\mathrm{NbC}$ particles under the same pouring temperature. The more first precipitated $\mathrm{NbC}$, the more austenite nucleus on the surface of $\mathrm{NbC}$ particles. Austenite and $\mathrm{NbC}$ particles were in coupled growth form (Zhou and Wang 1988), which effectively impeded the development of austenite dendrites. The effect of Ti additions on microstructure of the irons was similar to $\mathrm{Nb}$. TiC particles were mainly presented in austenite. Ti addition refined the secondary dendrite arm spacing, first precipitated $\mathrm{TiC}$ particles acted as nuclei for the austenite dendrites thereby refining this structure (Bedolla-Jacuinde et al 2007).

In addition, depletion of $\mathrm{C}$ caused by the formation of the first precipitated carbides implied the decrease of the amounts of primary $\mathrm{M}_{7} \mathrm{C}_{3}$ carbides. As for the slight hypereutectic HCCI in this work, more chromium dissolved in eutectic transition liquid. The compositions of the austenite in the matrix were conducted with EDS and the results were shown in table 2. It suggested that the chromium content in austenite increased with the increase of the amounts of alloy elements. According to the work (Shijian 1993), the solidification rate of eutectic structure increased with the increase of chromium content, so eutectic microstructure was refined.

However, when the alloy elements contents was D alloy, more high melted pointed particles would be formed above the eutectic temperature. It also led to the rapid merging and growth of first precipitation particles. When these first precipitation particles coarsen up to several micrometers, only a few residual small particles are suitable to play the role of austenite nucleation cores in the subsequent solidification. C alloy had eutectic composition, eutectic temperature was low, fluidity was good, thermal crack and segregation tendency were small, so it exhibited the best microstructure.

Table 2. Compositions of austenite in as-cast alloy determined by EDS (wt \%).

\begin{tabular}{lcccc}
\hline Elements & $\mathrm{A}$ & $\mathrm{B}$ & $\mathrm{C}$ & $\mathrm{D}$ \\
\hline $\mathrm{Cr}$ & 24.00 & $25 \cdot 22$ & $30 \cdot 23$ & 35.21 \\
$\mathrm{Fe}$ & 46.47 & 38.50 & 58.65 & 63.26 \\
$\mathrm{C}$ & - & 29.86 & $11 \cdot 12$ & - \\
$\mathrm{Mo}$ & - & 2.68 & - & - \\
$\mathrm{O}$ & 26.64 & 3.74 & - & - \\
\hline
\end{tabular}

\subsection{Influence of alloy elements addition on mechanical properties}

3.3a Hardness: Results of bulk hardness and impact toughness are presented in figure 8. As illustrated, they increased and then decreased with the increase of the amounts of alloy elements. The reasons of hardness variation were attributed to three factors. One of the favourable and beneficial factor was that alloy elements dissolved in austenite and improved austenite hardness by solid solution strengthening. Another advantageous factor was that hard first precipitated compounds were harder than the primary and eutectic $\mathrm{M}_{7} \mathrm{C}_{3}$ carbides. TiC and $\mathrm{NbC}$ were embedded in austenite to protect and strengthen the matrix. $\mathrm{V}$ existed in $\mathrm{M}_{7} \mathrm{C}_{3}$ carbides and increased the hardness of $\mathrm{M}_{7} \mathrm{C}_{3}$ carbides.

The deleterious factor was mainly attributed to the decrease of total carbide volume fraction with the increase of alloy element additions. It was well known that the formation of first precipitated carbides consumed certain carbon present in the alloy, so the total volume fracture of $\mathrm{M}_{7} \mathrm{C}_{3}$ was reduced. The relationship between total carbide volume fraction and carbon content (weight fraction) was described as follows (Shijian 1993):

$$
V_{\text {total }}=12 \cdot 33 \mathrm{C}+0 \cdot 55 \mathrm{Cr}-15 \cdot 2 .
$$

The decrease of carbides volume fraction implied to the decrease of bulk hardness. However, in the multicomponent systems, the comprehensive factors determined the ultimate hardness of material. It was observed that $\mathrm{C}$ alloy exhibited the best hardness with $58.9 \mathrm{HRC}$, this was attributed to the synthetic roles of alloy element solid solution strengthening, the formation of $\mathrm{TiC}, \mathrm{NbC}, \mathrm{V}$ alloy compounds and the appropriate ratio between austenite and hard phases.

3.3b Impact toughness and impact fractographic morphology: As shown in figure 8, C alloy had about 2 times better impact toughness than $\mathrm{A}$ alloy and reached to a maximum

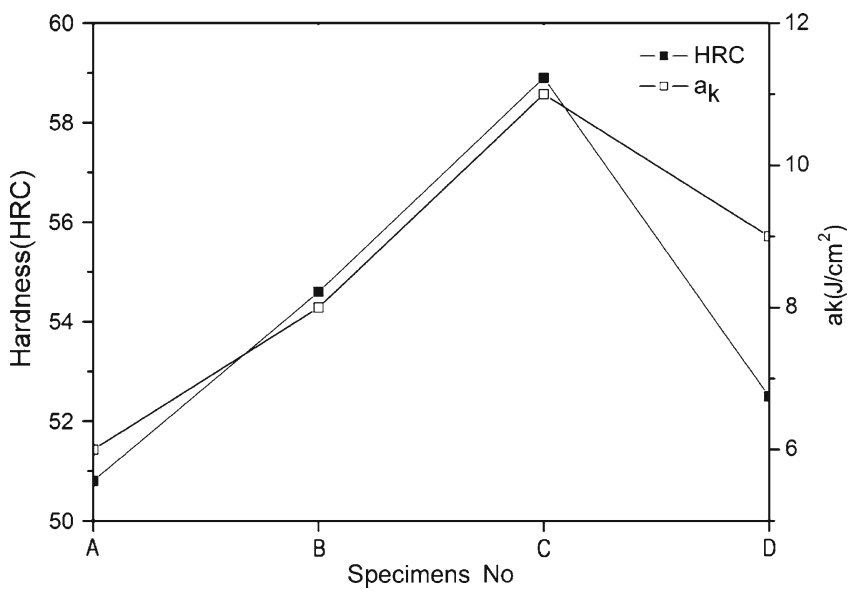

Figure 8. Influence of different alloy elements on hardness and impact toughness. 

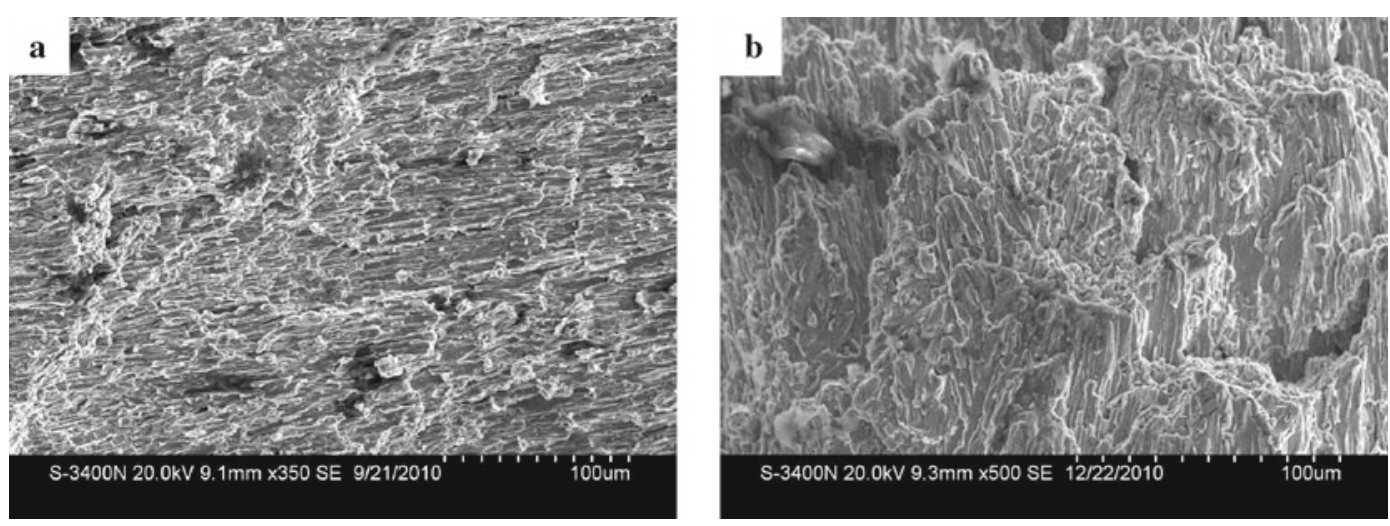

Figure 9. Impact fractography morphologies of (a) A and (b) $\mathrm{C}$ alloys.

value of $11 \mathrm{~J} / \mathrm{cm}^{2}$. The decrease of impact toughness value of D alloy with the highest alloy amounts was attributed to the carbides coarsening.

Fracture surfaces (figure 9) of the impact toughness samples were studied using SEM to elicit information on the fracture mode. It was revealed that the fracture modes of two kinds of irons were cleavage fracture. The fracture surface of A alloy was bright, fracture plane was remarkable and tearing ridge exhibited strong orientation. The tearing ridge of $\mathrm{A}$ alloy was longer and higher than that of $\mathrm{C}$ alloy.

The impact toughness not only had relationship with matrix, but also largely depended on the volume fraction, distribution, morphology, size of carbides and so on. Carbides of A alloy were coarse, the distribution of carbides were inhomogeneous (figure 1(a)), it indicated that the stress concentration factor was bigger when the material was exposed to impact. The microcracks of carbides propagated quickly along a certain direction with small resistance. When the crack front came into contact with carbides/austenite interface, brittle fracture occurred. C alloy had a fine eutectic microstructure with small size, well distribution and small spacing of carbides, which was beneficial to the mechanical behaviour of the alloy. These finer carbides weakened stress concentration and decreased crack propagation rate. When the alloy was subjected to impact, the stress on carbides can rapidly transport to the soft austenite. It was considered that austenite acted as a cushion of crack propagation preventing brittle cracks propagating directly from one carbide to another.

\section{Conclusions}

Solute $\mathrm{Ti}, \mathrm{Nb}$ and $\mathrm{V}$ atoms reacted with carbon and formed $\mathrm{TiC}, \mathrm{NbC}$ and $\mathrm{V}$ alloy compounds $\left(\mathrm{VCr}_{2} \mathrm{C}_{2}\right)$ under certain conditions in the melt of slight hypereutectic high chromium cast iron, resulting in the change in microstructure of the alloy from a hypereutectic form, eutectic one to hypoeutectic one with the increase of alloy elements additions. $\mathrm{Ti}$ and $\mathrm{Nb}$ additions refined austenite and $\mathrm{TiC}$ and $\mathrm{NbC}$ particles mainly existed in austenite. $\mathrm{V}$ addition decreased the eutectic solidification temperature interval, leading to the decrease of carbides spacing. With $0.60 \mathrm{wt} \%$ Ti-0.60 wt $\%$ V-0.60 wt $\%$ $\mathrm{Nb}-0.35 \mathrm{wt} \%$ Mo added, a fine eutectic microstructure was achieved. Under these conditions, the bulk hardness had a limited increase and the impact toughness was greatly increased and reached a maximum value of $11 \mathrm{~J} / \mathrm{cm}^{2}$.

\section{Acknowledgement}

This study was supported by Shanxi Province Office of Education (2010JK49) and the authors would like to acknowledge their support.

\section{References}

Bedolla-Jacuinde A, Correa R and Mej I 2007 Wear 263808 Chunga R J, Tanga X and Dolman K 2009 Wear 267502 Dai Y, Yang M and Song C 2010 Mater. Charact. 61116 Dupin P, Saverna J and Schissler J M 1982 AFS Trans. 90711 Filipovic M, Kamberovic Z and Korac M 2011 Mater. Trans. 52386 Fiset M, Peev K and Radulovic M 1993 J. Mater. Sci. Lett. 12615 Inthidech S and Boonmak K 2010 Mater. Trans. 511264 Izciler M and Celik H 2000 J. Mater. Process. Technol. 105237 Labrecque C and Gagne M 1998 Canadian Metal. Quart. 37343 Li F, Qijie Z and Guanghua Z 1996 Acta Metall. Sinica 32159 Liu H and Wang J 2007 Mater. Des. 281059

Lu L, Soda H and McLean A 2003 Mater. Sci. Eng. A347 214

Mousavi Anijdan S H and Bahrami A 2007 Mater. Sci. Eng. $\mathbf{A 4 5 4}$ 623

Ogi K, Matsubara Y and Matsuda K 1982 AFS Trans. 89197

Powell G L F 1980 Metals Form. 337

Qingyu H, Zhenyi H and Jingtao W 2009 J. Iron Steel Res. Int. 16 33

Qu Y, Xing J and Zhi X 2008 Mater. Lett. 623024

Shijian H 1993 High chromium wear resistance cast iron (Beijing: Coal Industry Press)

Xie G, Sheng H and Han J 2010 Mater. Des. 313062

Zhi X, Xing J and Fu H 2008a Mater. Lett. 62857

Zhi X, Xing J and Fu H 2008b Mater. Charact. 591221

Zhi X, Xing J and Fu H 2008c Materialwiss. Werkst 39391

Zhou D and Wang G 1988 Hot Work. Technol. 53 